\title{
FLUIDOS SUPERCRÍTICOS EM QUÍMICA ANALIITICA. II. CROMATOGRAFIA COM FLUIDO SUPERCRÍTICO: INSTRUMENTAÇÃO
}

Emanuel Carrilho, Maria Cecília H. Tavares e Fernando M. Lanças*

Instituto de Química de São Carlos, Universidade de São Paulo, CP 780, 13560-970 São Carlos - SP

Recebido em 12/6/02; aceito em 6/12/02

\begin{abstract}
SUPERCRITICAL FLUID IN ANALYTICAL CHEMISTRY. II. SUPERCRITICAL FLUID CHROMATOGRAPHY: INSTRUMENTATION. The first paper in this series discussed the basic theory involved in supercritical fluid chromatography (SFC) and how the technique progressed from gas and liquid chromatography. The first SFC instruments were simple adaptations of the commercially available liquid chromatographs with packed columns followed by modifications in gas chromatographs using open tubular capillary columns. In this paper, the most important aspects regarding instrumentation are covered, including practical, simple, and the most important, inexpensive solutions to build a home-made SFC system.
\end{abstract}

Keywords: instrumentation; SFC; home-made systems.

Conforme discutido em publicação anterior ${ }^{1}$, a cromatografia com fluido supercrítico (SFC) foi desenvolvida a partir do conhecimento já bem sedimentado da cromatografia gasosa (GC) e da cromatografia líquida (LC). Os primeiros cromatógrafos empregados para SFC foram simples adaptações de cromatógrafos comercialmente disponíveis para cromatografia líquida de alta eficiência (HPLC). A principal modificação instrumental geralmente consiste na adaptação de bombas de pressurização e de celas de detecção, principalmente do tipo UV-vis, para resistirem às pressões elevadas. Inicialmente, as colunas eram as mesmas usadas em HPLC. A introdução, no início da década de 80, dos tubos de sílica fundida para preparo de colunas capilares em cromatografia gasosa foi rapidamente absorvida em SFC. Assim, surgiram as colunas capilares (ou tubulares abertas) em SFC, as quais requeriam instrumentos diferentes daqueles já existentes para SFC usando colunas empacotadas (recheadas) provenientes da HPLC. Estabeleceram-se, então, duas modalidades de instrumentos para SFC: para colunas empacotadas (ou recheadas) (pSFC) ou para colunas capilares (tubulares abertas) (cSFC). No presente trabalho o uso dos dois tipos de coluna em SFC serão descritos e as vantagens e limitações da instrumentação pertinente serão discutidas.

\section{INTRODUÇÃO}

O esquema genérico ilustrado na Figura 1 mostra os principais componentes de um cromatógrafo utilizando fluido supercrítico como fase móvel. Na parte (A) da Figura 1, ilustra-se um sistema típico para uso com colunas empacotadas (recheadas) enquanto que na parte (B), é esquematizado um sistema para colunas capilares (tubulares abertas). Apesar do esquema genérico diferir apenas com relação às colunas, em decorrência de suas características, vários detalhes serão discutidos a seguir, uma vez que a otimização dos sistemas pode depender da escolha dos componentes.

\section{INSTRUMENTAÇÃO PARA SFC}

\section{Sistema de bombeamento e pressurização}

Sendo as pressões de trabalho em SFC geralmente elevadas, existe

\footnotetext{
*e-mail: flancas@iqsc.usp.br
}
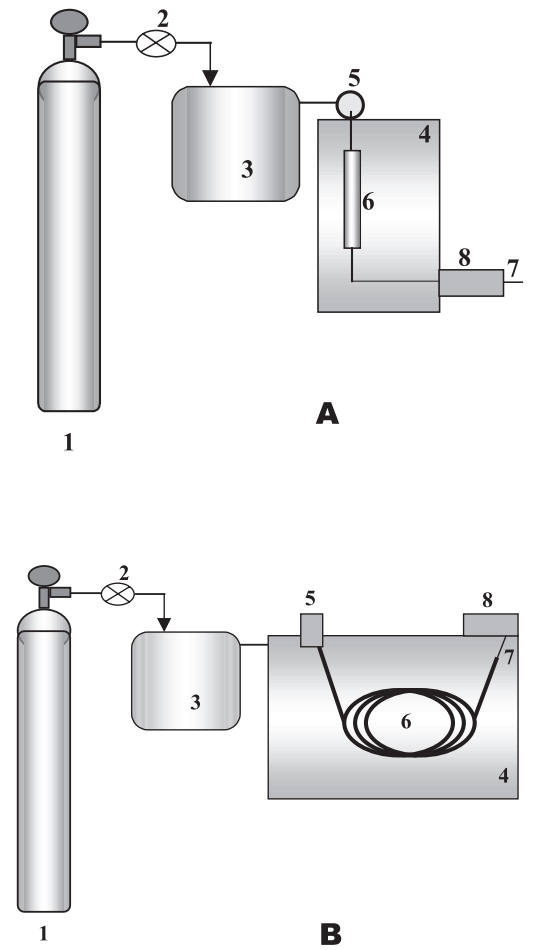

Figura 1. Diagrama de um cromatógrafo para pSFC (colunas empacotadas ou recheadas) (A) e de um cromatógrafo para cSFC (colunas capilares ou tubulares abertas) (B). 1- cilindro de $\mathrm{CO}_{2}, 2$-válvula, 3- bomba para pressurizar o $\mathrm{CO}_{2}$, 4-forno, 5- injetor, 6- coluna, 7-restritor, 8- detector

a necessidade de um maior cuidado sobre o sistema de bombeamento e pressurização. O sistema ideal para SFC deve ser capaz de suportar altas pressões, apresentar rápida resposta aos comandos de alteração da pressão e manter-se a níveis constantes com baixas flutuações no bombeamento do eluente. Todas os sistemas de pressurização apresentados e discutidos na Tabela 1 podem ser satisfatoriamente usados para SFC, porém a escolha vai depender do custo, do fluido empregado, da vazão compatível com a coluna empregada e da aplicação a ser realizada. 
Tabela 1. Características de três tipos de sistemas de pressurização para SFC

\begin{tabular}{|c|c|c|c|c|}
\hline Tipo de Bomba & Funcionamento & Vantagens & Limitações & Uso \\
\hline pressurização pneumática & $\begin{array}{l}\text { um líquido em um } \\
\text { recipiente metálico é } \\
\text { pressurizado diretamente } \\
\text { com nitrogênio (ou outro } \\
\text { gás inerte) }\end{array}$ & $\begin{array}{l}\text { é a opção mais fácil e } \\
\text { barata de se implementar } \\
\text { em um laboratório, pois } \\
\text { o vaso de pressurização } \\
\text { pode ser construído em } \\
\text { uma oficina mecânica } \\
\text { simples }^{2}\end{array}$ & $\begin{array}{l}\text { este sistema é bastante } \\
\text { limitado, uma vez que a } \\
\text { maior pressão disponível } \\
\text { de se obter é igual à } \\
\text { do cilindro de nitrogênio } \\
\text { (aproximadamente } \\
160 \text { bar) }\end{array}$ & $\begin{array}{l}\text { se o sistema dispuser de } \\
\text { uma boa válvula de alta } \\
\text { pressão, a programação } \\
\text { de pressão é possível, } \\
\text { podendo ser efetuados } \\
\text { incrementos contínuos }\end{array}$ \\
\hline pistão reciprocante & $\begin{array}{l}\text { é uma bomba típica de } \\
\text { HPLC; funciona com um } \\
\text { ou dois pistões de } \\
\text { pequeno volume que } \\
\text { alternadamente puxam o } \\
\text { líquido do reservatório e } \\
\text { o comprimem em direção } \\
\text { à coluna cromatográfica }\end{array}$ & $\begin{array}{l}\text { sistema amplamente } \\
\text { utilizado em HPLC; } \\
\text { é possível controlar } \\
\text { satisfatoriamente a } \\
\text { pressão e operar } \\
\text { facilmente com } \\
\text { programação de } \\
\text { composição de fase } \\
\text { móvel e/ou adição de } \\
\text { modificadores }\end{array}$ & $\begin{array}{l}\text { existe a necessidade de } \\
\text { instalação de um supressor } \\
\text { de pulso, eletrônico ou } \\
\text { mecânico, para se obter } \\
\text { um bombeamento livre de } \\
\text { pulsação }\end{array}$ & $\begin{array}{l}\text { se o fluido for líquido à } \\
\text { temperatura ambiente, } \\
\text { nenhuma modificação é } \\
\text { necessária, porém se o } \\
\text { fluido for um gás, então } \\
\text { é necessário refrigerar } \\
\text { a bomba }\end{array}$ \\
\hline seringa & $\begin{array}{l}\text { funciona como um pistão } \\
\text { único, porém de grande } \\
\text { volume }(\sim 20 \mathrm{~mL})\end{array}$ & $\begin{array}{l}\text { é a mais indicada para o } \\
\text { uso em SFC pois } \\
\text { apresenta fluxo estável, } \\
\text { rápida resposta à } \\
\text { programação e permite } \\
\text { também a utilização de } \\
\text { gases como fluido } \\
\text { supercrítico, desde que } \\
\text { estejam no estado } \\
\text { líquido (para tal é } \\
\text { necessário resfriar o } \\
\text { sistema antes da } \\
\text { pressurização) }\end{array}$ & $\begin{array}{l}\text { sem dúvida, a bomba } \\
\text { seringa é a opção de } \\
\text { melhor desempenho por } \\
\text { ser livre de pulsação e } \\
\text { por atingir altas pressões, } \\
\text { porém também é a de } \\
\text { maior custo e não } \\
\text { permite mudança rápida } \\
\text { de composição de fase } \\
\text { móvel }\end{array}$ & $\begin{array}{l}\text { a seringa é preenchida com } \\
\text { o fluido na composição a } \\
\text { ser usado, podendo ser } \\
\text { usado tanto com vazão } \\
\text { ou pressão constantes ou } \\
\text { com gradiente de } \\
\text { densidade }\end{array}$ \\
\hline
\end{tabular}

\section{Injetores}

Vários autores pioneiros chegaram a construir seus próprios injetores. Jentoft e Gouw ${ }^{5}$ montaram um injetor de alta pressão do tipo "stop flow". Sie e Rijnders ${ }^{6}$ descreveram um sistema onde a amostra era injetada pneumaticamente para dentro da coluna. Atualmente estão sendo desenvolvidos sistemas de injeção de amostras para alta pressão baseados no tempo ${ }^{7}$, os quais possibilitam a injeção de volumes bastante reduzidos com alta precisão e exatidão.

O injetor convencional de GC, o qual permite inserção direta da agulha de uma seringa em um septo, foi usado apesar de apresentar problemas em sistemas com a pressão inicial elevada (geralmente quando a pressão crítica do eluente é maior que 70 bar), mas mostrou bom desempenho a pressões menores (fluidos com pressão crítica em torno de 40 bar ${ }^{8}$. Sem dúvida alguma, o sistema mais usado é o injetor típico de HPLC com válvula de múltiplos pórticos. Este injetor apresenta alto desempenho em pressões elevadas e boa reprodutibilidade de amostragem. Para colunas em pSFC, um sistema convencional de injeção para HPLC é adequado. Entretanto, para sistemas com coluna capilar, um volume menor de amostra é necessário. Para tal, deve-se adaptar um "split" (divisor de amostra) entre o injetor e a coluna. Os injetores mais antigos utilizavam um volume grande de amostra, geralmente com "loop" externo", enquanto que os mais modernos já apresentam "loop" interno da ordem de nanolitros, o que diminui a relação de divisão ("split ratio"). As dimensões da coluna capilar regulam a capacidade máxima de amostra a ser injetada. Na Tabela 2 são apre-
Tabela 2. Volumes típicos de injeção $\left(\mathrm{V}_{\text {inj }}\right)$ em função do diâmetro interno (d.i.) e comprimento (L) da coluna capilar em SFC ${ }^{10}$

\begin{tabular}{ccc}
\hline $\begin{array}{c}\text { Diâmetro interno } \\
\text { d.i. }(\mu \mathrm{m})\end{array}$ & $\begin{array}{c}\text { Volume do injetor } \\
\mathrm{V}_{\text {inj }}(\mu \mathrm{L})\end{array}$ & $\begin{array}{c}\text { Comprimento da coluna } \\
\mathrm{L}(\mathrm{m})\end{array}$ \\
\hline 200 & 1,50 & 4,8 \\
100 & 0,27 & 3,4 \\
50 & 0,05 & 2,4 \\
\hline
\end{tabular}

sentadas algumas relações de volume de injeção em função do diâmetro e comprimento da coluna ${ }^{10}$.

\section{Colunas}

As primeiras tentativas na utilização de colunas capilares em cromatografia com fluido supercrítico foram frustradas pelo fato de que várias fases estacionárias foram lavadas da coluna pelo alto poder de solvatação do fluido supercrítico. Isto levou os pesquisadores a desenvolverem fases de maior massa molecular (entrecruzadas) e com ligação direta ao suporte sólido (tubo de sílica fundida no caso de colunas capilares ou partículas de sílica no caso de colunas empacotadas). O tamanho das partículas de empacotamento (recheio) tem grande influência no desempenho cromatográfico devido ao seu efeito na queda de pressão ao longo da coluna. Partículas de tamanho pequeno $(1 \mathrm{a} 10 \mu \mathrm{m})$ permitem elevada resolução cromatográfica e gran- 
de número de pratos (eficiência elevada), porém a queda de pressão é grande, da ordem de 5 a 10 bar, o que causa efeitos adversos. Por outro lado, partículas de diâmetro maior (20 a 120 нm) apresentam menor eficiência devido à menor área de partição, porém produzem pequena queda de pressão (quase desprezível em alguns sistemas, da ordem de 0,5 bar) o que permite o uso de vazões de fase móvel maiores, reduzindo o tempo de análise.

A escolha da fase estacionária deve ser feita levando em consideração o soluto a ser analisado e a estabilidade da fase sob as condições críticas; neste aspecto, tanto o filme líquido quanto o suporte sólido devem ser considerados. Tanto colunas empacotadas quanto colunas capilares de tubo aberto podem ser usadas em SFC. A diferença entre os sistemas não recai somente nos dois tipos de coluna mas, também, na fase estacionária, na instrumentação e na aplicação dessas diferentes formas de SFC. A teoria básica, todavia, é igualmente válida para ambas situações. As características mais relevantes de cada tipo de coluna serão destacadas a seguir:

- Características de uma coluna capilar tubular aberta para cSFC:

Na coluna capilar de tubo aberto a fase estacionária é um filme polimérico depositado na parede interna do tubo. O volume da coluna, exceto aquele ocupado pela fase estacionária, é disponível para o fluxo da fase móvel. Para uma dada coluna, três dimensões são relevantes: o diâmetro interno da coluna, a espessura de filme da fase estacionária e o comprimento da coluna.

a) Diâmetro interno (d.i.): a variação do diâmetro afeta a eficiência pois acarreta numa variação da vazão da fase móvel pela coluna alterando várias propriedades cromatográficas.

b) Comprimento: o aumento no comprimento causa um aumento na resolução assim como um aumento no tempo de análise. O comprimento da coluna deve ser o menor possível, porém suficiente para ocorrer a separação.

c) Espessura de filme $\left(\mathrm{d}_{\mathrm{f}}\right)$ : se $\mathrm{d}_{\mathrm{f}}$ é aumentado, pode-se aumentar o equivalente na amostra injetada na coluna, obtendo-se um aumento na sensibilidade.

- Características de uma coluna empacotada para pSFC:

O tamanho de partícula é um parâmetro adicional que afeta a eficiência e a sensibilidade. Os efeitos do tamanho de partícula na pSFC são similares aos efeitos do diâmetro da coluna na cSFC. As partículas usadas nas colunas de pSFC são as mesmas usadas para HPLC. O comprimento e o diâmetro interno das colunas para pSFC são mais limitadas que em HPLC devido à alta pressão utilizada e à maior restrição da primeira quanto a queda de pressão. A queda de pressão ocorre através da coluna e depende do diâmetro da partícula de empacotamento e do comprimento da coluna, podendo ser estimada pela Equação 1:

$\Delta P=\frac{u \psi \eta L}{d_{p}^{2}}$

onde: $\Delta P=$ pressão (bar)

$u=$ velocidade linear $(\mathrm{cm} / \mathrm{s})$

$\psi=$ constante $(\sim 1000$ para partículas esféricas de empacotamento)

$\eta=$ viscosidade (poise)

$L=$ comprimento da coluna $(\mathrm{cm})$

$d_{p}=$ diâmetro da partícula de empacotamento $(\mathrm{mm})$

O maior problema da variação da pressão através da coluna é que a densidade do fluido de arraste no início e no final da coluna serão diferentes e, conseqüentemente, o poder de solvatação será diretamente proporcional à variação da densidade do fluido e, com isso, o poder de eluição varia dentro da coluna ${ }^{11}$. Um resumo das vantagens e desvantagens do uso das colunas capilares e empacotadas é apresentado na Tabela 3.

Tabela 3. Resumo das características do emprego das colunas capilares e empacotadas em $\mathrm{SFC}^{12}$

\begin{tabular}{ll}
\hline Coluna capilar & \\
\hline Vantagens: & - Baixa queda de pressão \\
& - Alta eficiência \\
& - Facilidade de interface com detectores FID e \\
& MS \\
& Baixa vazão de fase móvel (bomba seringa) \\
\hline Desvantagens: & - Baixa velocidade ótima \\
& - Difícil controle de vazão \\
& Baixa sensibilidade com detectores UV e IR \\
\hline Coluna empacotada \\
\hline Vantagens: & - Menor tempo de análise \\
& - Alta capacidade de amostra (sensibilidade) \\
& Possibilidade de uso de detectores UV e IR \\
\hline Desvantagens: & Alta queda de pressão \\
& - Baixa eficiência \\
& Grande área superficial (possível efeito de \\
& adsorção) \\
\hline
\end{tabular}

\section{Sistema de aquecimento e controle de temperatura}

O controle da temperatura em SFC é muito importante pois a variação da temperatura acarreta variação da densidade do fluido e, conseqüentemente, influencia na partição, na volatilização dos analitos e na seletividade, principalmente na região próxima ao ponto crítico. Nesta região, isto é, em torno do ponto crítico, o controle da temperatura deve ser o melhor possível para manter a densidade do fluido constante. $\mathrm{O}$ forno cromatográfico deverá funcionar numa faixa desde a temperatura ambiente até cerca de $300{ }^{\circ} \mathrm{C}$. Em alguns casos há necessidade de ter um pré-aquecedor para que o fluido chegue na coluna com a temperatura próxima da qual será usada. Para isso, pode-se instalar o injetor dentro do forno; desta forma a amostra é introduzida na coluna sob a mesma temperatura de análise.

O sucesso do transporte do analito até o detector também depende da volatilidade, da solubilidade na fase fluida, da geometria do restritor, da pressão e da temperatura do fluido. Para compostos pouco voláteis, é possível que o analito precipite e concentre-se na parede do restritor, o qual pode chegar à ponta e, eventualmente, obstruir o restritor. A Figura 2 mostra uma foto dos diferentes perfis de expansão da água, em função da temperatura do restritor ${ }^{13}$. Pode-se perceber que a temperaturas mais elevadas o aerossol é mais fino e evita o entupimento do restritor. Para evitar a obstrução do restritor, a temperatura na zona de expansão do fluido deve ser maior que a temperatura crítica. $\mathrm{O}$ aumento da pressão facilita o transporte de analitos no sistema cromatográfico devido ao alto poder de solubilização do fluidos, mas aumentar a temperatura pode ser contraproducente uma vez que a densidade da fase fluida diminui. Para analitos que apresentam alguma volatilidade, o aumento da temperatura pode aumentar a solubilidade.

\section{Restritores}

Os restritores são usados para que se mantenha a pressão homogênea dentro da coluna cromatográfica. Os restritores são os ele- 


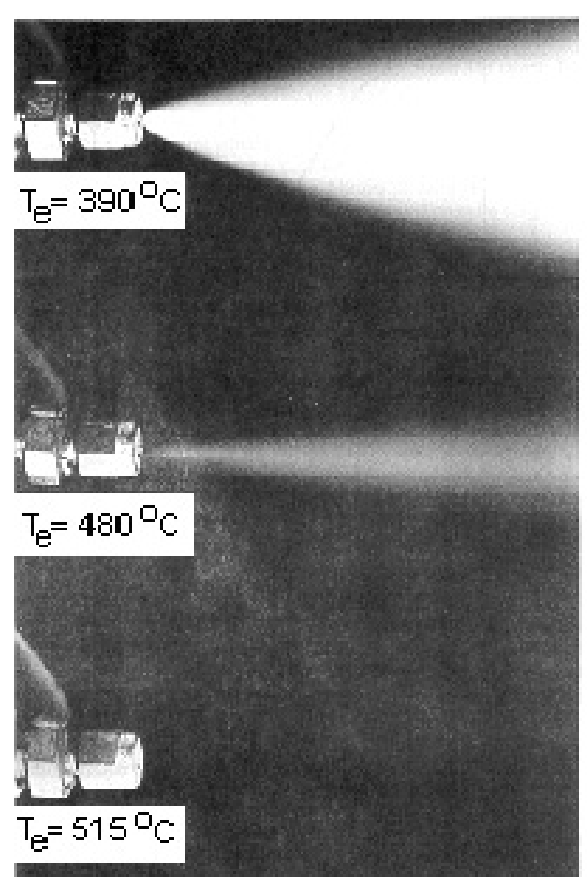

Figura 2. Fotografia do perfil da expansão da água para 600 bar em várias temperaturas de expansão (Te) - reproduzida da ref. 13, com permissão da American Chemical Society

mentos da instrumentação em SFC que devem apresentar os maiores cuidados na escolha devido à compatibilidade com os diferentes detectores, além de manterem a pressão interna constante. Na tentativa de obter resultados satisfatórios e consistentes, diversas possibilidades foram testadas. Por exemplo, Lee e Campbell ${ }^{14}$ montaram um sistema dotado de vasos de coleta pressurizados com nitrogênio, servindo para duas finalidades: recuperar a amostra em frações distintas e produzir uma pressão de retorno ("back pressure"). Sistema análogo foi descrito por Hirata e Nakata ${ }^{15}$ onde a "back pressure" era produzida por outra bomba de pressurização equilibrando, assim, a pressão de entrada e a pressão de saída.

Restritores mais simples são constituídos de tubo de sílica fundida de pequeno diâmetro interno $(<10 \mu \mathrm{m})$ como o utilizado por McNair e Hensley ${ }^{16}$. Bertsch e Green ${ }^{17}$ compararam 5 tipos de restritores: restritor de sílica fundida, restritor de sílica fundida não tratada, restritor de aço inox, restritor de vidro Pyrex e restritor de filtro sinterizado microporoso, tendo obtido um melhor resultado com o primeiro. A Figura 3 ilustra, de forma esquemática, diferentes geometrias de restritores que foram investigados para SFC e SFC$\mathrm{MS}^{18-23}$.

Muitos dos detectores usados para SFC, como o detector de ionização de chama (FID) e o espectrômetro de massas (MS), requerem que o efluente cromatográfico seja despressurizado antes da detecção. A despressurização é, geralmente, realizada pela expansão da fase móvel através do restritor na região onde ocorre a detecção. Muitos instrumentos empregados em SFC utilizam alguma forma de restritor capilar com dimensões empiricamente selecionadas para dar à fase móvel uma velocidade linear adequada para a temperatura e pressão cromatográficas desejadas.

Na Figura 4 é ilustrado o processo adiabático no qual a entalpia do fluido é a mesma antes e depois da expansão $\left(\mathrm{H}_{1}\right)$. Se o restritor for curto, o processo pode ser considerado adiabático, se o restritor for longo e a temperatura for mantida constante, a expansão poderá ser considerada isotérmica. Em ambos os casos, o estado de equilíbrio do fluido, no restitor e após a expansão, podem ser expressos

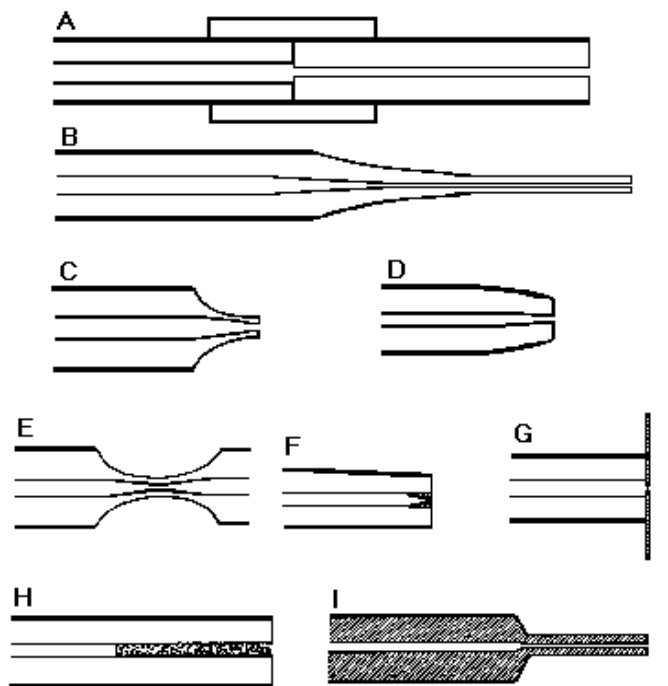

Figura 3. Diagrama de vários restritores que podem ser usados para SFC. A)de sílica fundida com redutor, B) de sílica fundida com extremidade cônica, C) e D) de sílica fundida com diferentes diâmetros de orifício, E) de sílica fundida com orifício interno formado a partir da compressão da coluna à temperatura elevada, F) formado pela deposição de material no final do capilar, G) de orifício tipo "pinhole", muito usado para SFC-MS, H) de sílica fundida formada por filtro poroso ("frit"), I) Restritor com a extremidade comprimida ("pinched"). Adaptado da ref. 21

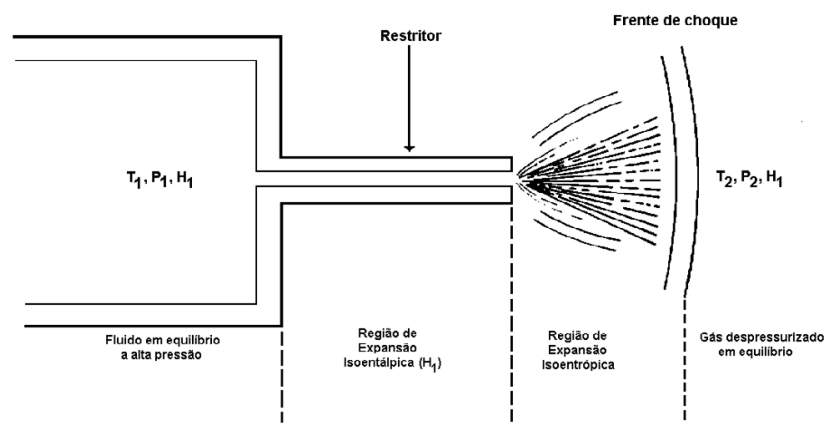

Figura 4. Ilustração esquemática da expansão do fluido supercrítico para um processo adiabático no qual os estados inicial e final do fluido são conhecidos - reproduzida da ref. 13, com permissão de American Chemical Society

pelas relações termodinâmicas descritas nas Equações 2 e $3^{1}$. A densidade do fluido na saída do capilar $\left(\rho_{2}\right)$ pode ser estimada pela relação entre as pressões após o processo de expansão $\left(P_{2}\right)$ e a pressão no interior da coluna $\left(P_{1}\right)$.

$\frac{\rho_{2}}{\rho_{1}}=\left(\frac{1+\gamma}{2}\right) \frac{P_{2}}{P_{1}}=1,2\left(\frac{P_{2}}{P_{1}}\right)$, sendo $\gamma=\frac{C_{p}}{C_{v}}=1,4$ para o $\mathrm{CO}_{2}$

onde: $\rho_{1}=$ densidade do fluido na entrada do capilar $\left(\mathrm{g} / \mathrm{cm}^{3}\right)$

$\rho_{2}=$ densidade do fluido na saída do capilar $\left(\mathrm{g} / \mathrm{cm}^{3}\right)$

$P_{1}=$ pressão no interior da coluna (bar)

$P_{2}=$ pressão após o processo de espansão (bar)

$\gamma=$ razão entre a capacidade calorífica a pressão constante $\left(C_{p}\right)$ e a volume constante $\left(C_{v}\right)$ 
Para uma expansão adiabática a temperatura na saída do capilar $\left(\mathrm{T}_{2}\right)$ será dada, também, pela relação entre a temperatura no interior da coluna $\left(\mathrm{T}_{1}\right)$ e $\gamma$.

$\frac{\mathrm{T}_{2}}{\mathrm{~T}_{1}}=\frac{2}{1+\gamma}$

As dimensões dos restritores podem ser as mais variadas possíveis e produzir o mesmo resultado. Por exemplo, o restritor capilar pode ser curto com um diâmetro interno bastante reduzido ou longo com diâmetro interno maior. $\mathrm{O}$ diagrama da Figura 5 mostra a dependência da relação entre o comprimento e o diâmetro do restritor capilar (L/D) e o efeito desta relação na redução do fluxo de fase móvel e na redução da pressão. O restritor ideal para SFC deve apresentar as seguintes características ${ }^{24}$ :

a) manter uma vazão uniforme, mesmo durante a programação de temperatura e pressão;

b) ser inerte para não permitir adsorção de analitos durante a despressurização da fase móvel;

c) ser facilmente substituído para variação de vazão e

d) manter a transferência completa de solutos que se degradam ou que não são voláteis ao detector sem pirólise ou formação de partículas.

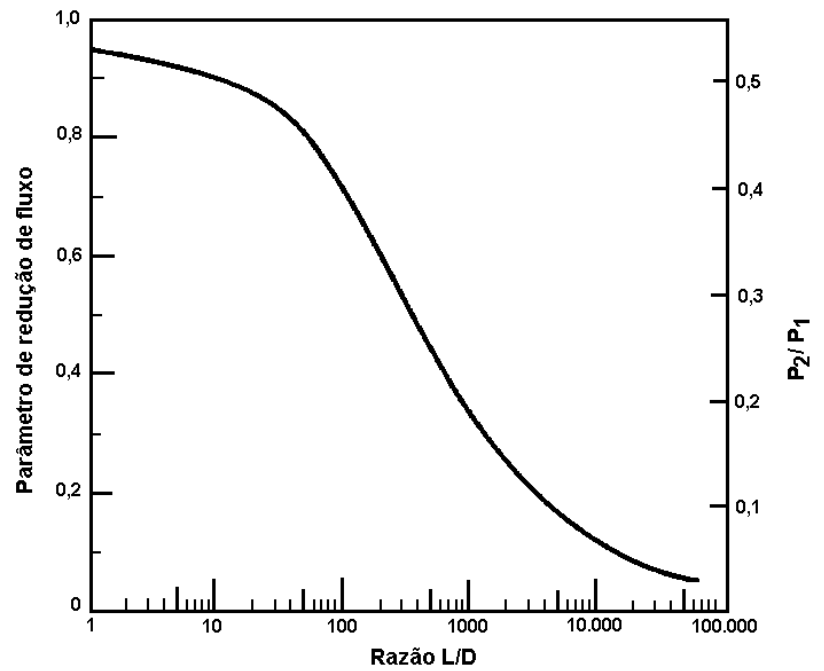

Figura 5. Parâmetros de redução de fluxo como uma função da razão comprimento/diâmetro da coluna $(L / d)$ para uma expansão adiabática no final do capilar - reproduzida da ref. 13, com permissão da American Chemical Society

\section{Detectores}

A princípio, qualquer detector convencional de cromatografia líquida ou gasosa pode ser usado em SFC sem que, para isso, necessite de grandes modificações instrumentais. Detectores de UV são amplamente usados desde que estejam dotados de uma cela de alta pressão ${ }^{25}$. Normalmente, os detectores de absorção UV apresentam bons resultados na análise de hidrocarbonetos aromáticos polinucleares. Pode-se adaptar um detector UV para detecção "oncolumn" devido ao reduzido volume de cela, quando a separação é feita em $\mathrm{cSFC}^{26}$. As desvantagens destes detectores são as mesmas encontradas em HPLC, como a ausência de resposta para compostos que não possuam grupos cromóforos. Um detector que tem sido usado com bons resultados por ser compatível com os dois sistemas SFC é o detector evaporativo com espalhamento de luz (ELSD). O ELSD é particularmente adequado para uso em SFC. O seu funcio- namento consiste numa etapa de vaporização do efluente com posterior espalhamento de luz pelas moléculas dos analitos, o que ocorre automaticamente no processo de descompressão da fase móvel. Este detector ainda apresenta boa sensibilidade, podendo ser considerado um detector pseudo-universal ${ }^{27}$.

Mais sensível e mais abrangente é o detector por ionização em chama, FID, largamente utilizado em GC, o qual permite a detecção da maioria dos compostos orgânicos com boa sensibilidade e excelente linearidade de resposta, sendo adequado para análises quantitativas. Alguns problemas foram encontrados na utilização de restritores antes do FID, incluindo o resfriamento nas regiões de expansão adiabática ${ }^{13} \mathrm{e}$ a deposição de material de alta massa molecular durante a descompressão da fase móvel ${ }^{28}$. Se o fluido é liquido à temperatura ambiente (tal como pentano) o detector mais indicado é o UV, enquanto que o FID é o detector preferido quando se utiliza $\mathrm{CO}_{2}$ como fluido supercrítico. Alguns trabalhos recentes avaliam o uso de espectrômetros de massas como detectores em $\mathrm{SFC}^{29}$. Apesar de promissores, sistemas dedicados SFC-MS ainda são raros e indisponíveis comercialmente ${ }^{30}$.

A expectativa de alta eficiência combinada com o baixo fluxo volumétrico mostrou que a SFC possibilita fácil interfaceamento com os detectores da cromatografia gasosa, em particular, com a espectrometria de massas. O grande interesse nesta técnica está na separação de compostos não polares de elevada massa molecular, como oligômeros sintéticos e surfactantes não-iônicos, que podem ser separados por SFC e apresentam a vantagem da detecção por MS. Assim, a caracterização de misturas complexas certamente foi beneficiada com esta evolução.

No início do desenvolvimento da SFC-MS não foi obtido um progresso substancial pois não houve a possibilidade de acoplamento direto. Foram feitas várias tentativas usando bombas de alto vácuo em estágios adicionais para tolerar altas vazões de fase móvel ${ }^{31-33}$. Com o desenvolvimento de novas colunas e diferentes interfaces, o interesse pela SFC-MS voltou a aumentar com vários trabalhos mostrando o sucesso neste interfaceamento ${ }^{34}$.

Durante a última década, a interface mais comum de SFC-MS era feita pela inserção direta do restritor na fonte de íons do espectrômetro de massas, podendo este operar tanto no modo de impacto eletrônico (EI) como em ionização química (CI). Por várias razões, este método de introdução direta de fluido mostrou-se efetivo:

a) o volume reduzido de fase móvel dispensada pela coluna capilar pode ser facilmente removido pelo sistema de vácuo do espectrômetro de massas padrão, sem a necessidade de estágios adicionais de vácuo;

b) apresenta um volume morto mínimo e

c) com o aquecimento suficiente da ponta do restritor pode-se compensar o resfriamento adiabático.

A influência do restritor no desempenho da interface do MS foi estudada $^{35}$. Entre os restritores comuns de SFC, o afilado de parede delgada fornece inigualável vantagem na separação de algumas misturas de oligômeros, os quais não podem ser completamente resolvidos quando se usa um restritor de filtro poroso ("frit") ou um integral ${ }^{36}$. Duas das possíveis interfaces utilizadas para o acoplamento SFC-MS com introdução direta da amostra estão mostradas na Figura 6.

Os primeiros equipamentos adaptados para acoplamento LC-MS suportavam altas vazões de fase móvel, podendo esta ser variada sem influenciar o mecanismo da produção de íons. Com este ponto de vista, a SFC tornou-se interessante novamente. A maior parte dos trabalhos em SFC-MS com ionização à pressão atmosférica (API) têm sido realizados com colunas capilares ${ }^{39-41}$. Para a interface SFC com fonte API, equipamentos LC-MS comerciais foram usados sem modificações, requerendo somente a introdução de um restritor. Alguns problemas podem surgir quando o instrumento apresentar um 

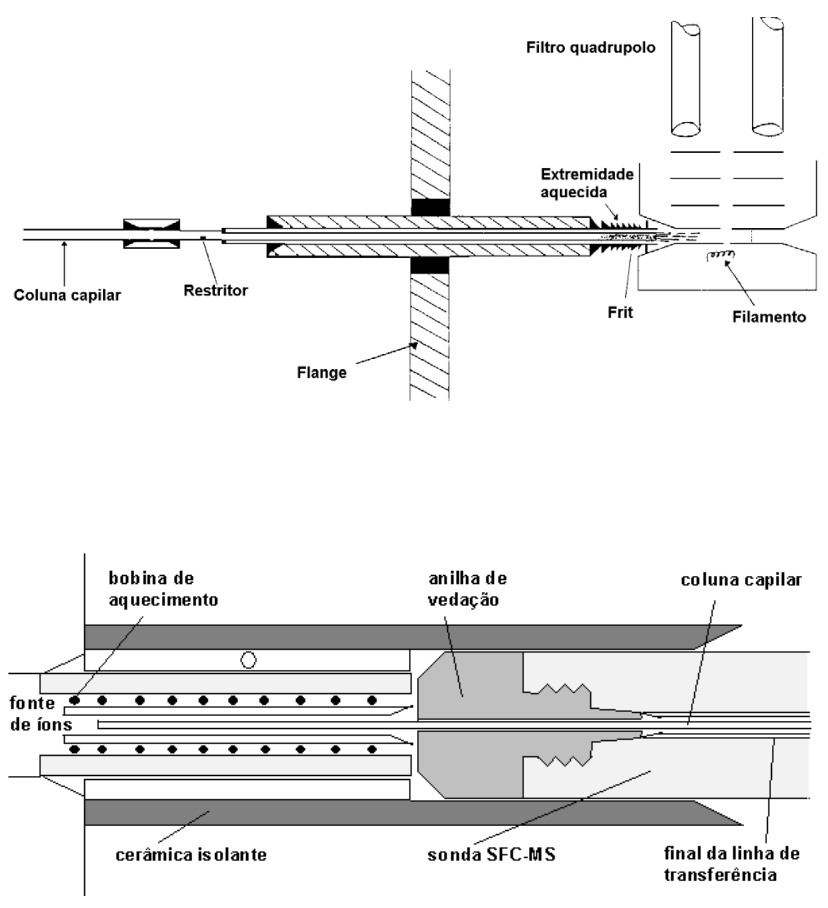

Figura 6. Diagramas de duas interfaces SFC-MS - reproduzidos das ref. 37 e 38, com permissão de Wiley - VCH

restritor não apropriado. Uma limitação no uso de fonte API está na utilização de uma composição programada (gradiente) da fase móvel em SFC $^{39,40}$.

Há dois mecanismos fundamentais no processo de ionização do soluto em efluente SFC à pressão atmosférica. Primeiro, a ionização pode ser executada na fase gasosa por meio de uma descarga "Corona" produzida com a aplicação de uma alta tensão na ponta de um eletrodo agulha, localizado na saída do restritor. Este processo é denominado de ionização química a pressão atmosférica (APCI) e requer uma vaporização completa do efluente da coluna, a qual é auxiliada pelo aquecimento do restritor e de um nebulizador de gás. $\mathrm{O}$ segundo mecanismo dá-se por um processo de nebulização sob alta tensão ou "electrospray". A ionização "electrospray" (ESI) dá-se inicialmente pela formação de gotículas finas no aerossol na saída da coluna. Com a vaporização constante destas microgotas, a presença de cargas provenientes dos analitos iônicos ou de tampões ácidos provoca uma grande repulsão eletrostática na superfície da gota. No limite da estabilidade entre a tensão superficial e a repulsão iônica ocorre uma explosão coulômbica, a qual ocorre sucessivamente até o analito se encontrar ionizado em fase gasosa. Este processo é particularmente interessante para macromoléculas ${ }^{41-43}$.

\section{Sistemas comerciais}

Um indício de que existe uma demanda em crescimento para instrumentos comerciais de SFC pode ser observado pelo número atual de fabricantes de equipamentos. Por exemplo, em 1994, apenas Hewlett Packard, Dionex, Suprex e Gilson tinham modelos de instrumentos disponíveis no mercado. Em 1997, das quatro companhias iniciais, apenas a Gilson ainda se mantinha ativa na área de SFC, porém, na companhia de outros seis fabricantes que, ou criaram os próprios modelos ou licenciaram dos primeiros. Juntos ofereciam oito modelos diferentes de equipamentos, sendo que todos dedicados a colunas empacotadas (tanto para colunas "microbore" quanto para colunas analíticas e preparativas). Uma exceção era a ABB Process Analytics, que oferecia a possibilidade de escolha entre colunas capilares e empacotadas. Para uma completa comparação entre todos os sistemas comerciais disponíveis veja as Revisões de Produto ("Product Review") nas Páginas A do periódico Analytical Chemistry ${ }^{30,44}$.

\section{COMENTÁRIOS FINAIS}

O ressurgimento da SFC ainda é tímido, todavia ele é inegável ${ }^{44}$. A indústria farmacêutica está sendo sua principal promotora por ter encontrado na SFC uma ferramenta analítica particularmente apropriada para seus compostos de interesse. Compostos farmacêuticos são, em sua grande maioria, ou compostos termicamente instáveis, ou de baixa volatilidade ou compostos quirais. Estes últimos, constituem no principal foco das aplicações na indústria farmacêutica, pois SFC normalmente gera uma resolução maior por unidade de tempo do que HPLC em separações quirais, o que é extremante interessante para aplicações industriais ${ }^{45}$. Curiosamente, aparentemente o efeito de solvatação do dióxido de carbono induz mudanças conformacionais que são geometricamente favoráveis à discriminação quiral ${ }^{46}$.

Nos últimos 2 anos pouco foi mudado na instrumentação comercial em SFC e os instrumentos adaptados ainda estão sendo usados e testados com pequenas variações para utilização com coluna capilar e diferentes detectores, como o $\mathrm{MS}^{47}$. Depois de um período de quase estagnação, trabalhos realizados pelo uso de técnicas API durante os últimos anos têm dado um novo ímpeto no campo da SFC-MS. Observa-se que existe uma grande oportunidade se abrindo no interfaceamento pSFC-MS sem restrições às limitações cromatográficas, obtendo-se, assim, uma poderosa ferramenta analítica, muito mais versátil que cSFC-MS, a qual tem dominado os trabalhos em SFCMS nos anos recentes.

Atualmente, há ainda um número reduzido de grupos de pesquisa trabalhando em SFC-API-MS, parcialmente devido aos altos custos dos equipamentos. Particularmente, a fonte API tem sido usada apenas em escala de pesquisa em instrumentos MS adaptados. Contudo, uma vez que equipamentos miniaturizados poderão ser feitos e disponíveis, espera-se que SFC-MS terá uma ampla aceitação.

Outra grande potencialidade do acoplamento SFC-MS está relacionada com o desenvolvimento da cromatografia unificada ${ }^{48}$, na qual o grande desafio é compatibilizar a fase móvel com o sistema de detecção. Neste caso, usando $\mathrm{CO}_{2}$ e MS, pode-se utilizar a fase móvel em qualquer estado (líquido, gás ou supercrítico) e um sistema de detecção universal.

Será apresentada, nos próximos artigos, uma avaliação de dois sistemas para cromatografia com fluido supercrítico, sendo um para colunas empacotadas e o outro para colunas capilares abertas. Ambos foram projetados e construídos pelo Grupo de Cromatografia (CROMA) do Instituto de Química de São Carlos/USP. O primeiro, uma versão completamente artesanal, foi montado e adaptado a partir de alguns componentes cromatográficos antigos e outros desenhados e construídos no IQSC ${ }^{2}$. O segundo, já mais sofisticado e moderno, foi construído com correções observadas no desenvolvimento do primeiro sistema, empregando uma coluna capilar de tubo aberto $^{49}$.

\section{AGRADECIMENTOS}

Os autores agradecem às agências de fomento FAPESP, CAPES e CNPq pelo suporte financeiro por meio de auxílios à pesquisa e bolsas de estudo e de produtividade, respectivamente. 


\section{REFERÊNCIAS}

1. Carrilho, E.; Tavares, M. C. H.; Lanças, F. M.; Quim. Nova 2001, 24, 509.

2. Carrilho, E.; Lanças, F. M.; Ciência e Cultura, Sup. 1988, 40, 431.

3. Miller Jr., T. E.; Davis, C. M.; Anal. Chem. 1988, 60, 1965.

4. Lesellier, E.; Analusis 1999, 27, 241.

5. Jentoft, R. E.; Gouw, T. H.; J. Chromatogr. Sci. 1970, 8, 138.

6. Sie, S. T.; Rijnders, G. W. A.; Sep. Sci. Technol. 1967, 2, 729.

7. Nixdorf, S. L.; Camara, C. A.; Mazo, L. H.; Oliveira, P. C.; Lanças, F. M.; J. Microcolumn Sep., no prelo.

8. Tong, D. X.; Barnes, A. M.; Bartle, K. D.; Clifford, A. A.; J. Microcolumn Sep. 1996, 8, 353.

9. Kohler, J.; Rose, A.; Schomburg. G.; J. High Resol. Chromatogr. 1988, $11,191$.

10. Peaden, P. A.; Lee, M. L.; J. Chromatogr., A 1983, 259, 1.

11. Shen, Y.; Lee, M. L.; Anal. Chem. 1998, 70, 737.

12. Shoenmakers, P. J. Em Supercritical Fluid Chromatography; Smith, M., ed.; Royal Society of Chemistry: London, 1988.

13. Smith, R. D.; Fulton, J. L.; Petersen, R. C.; Kopriva, A. J.; Wright, B. W.; Anal. Chem. 1986, 58, 2057.

14. Campbell, R. M.; Lee, M. L.; Anal. Chem. 1986, 58, 2247.

15. Hirata, Y.; Nakata, F.; Chromatographia 1986, $21,627$.

16. Hensley, J. L.; McNair, H. M.; J. Liq. Cromatogr. Relat. Technol. 1986, 9 , 1985.

17. Green, S.; Bertsch, W.; J. High Resol. Chromatogr. 1988, 11, 414.

18. Chester, T. L.; J. Chromatogr., A 1984, 299, 424.

19. Smith, R. D.; Fjeldsted, J. C.; Lee, M. L.; J. Chromatogr., A 1982, 247, 241.

20. Guthrei, E. J.; Schwartz, H. E.; J. Chromatogr. Sci. 1986, 24, 236.

21. White, C. M.; Gere, D. R.; Boyer, D.; Pacholec, F.; Wong, L. K.; J. High Resol. Chromatogr. \& CC 1988, 11, 94

22. Markides, K. E.; Fields, S. M.; Lee, M. L.; J. Chromatogr. Sci. 1986, 24, 254.

23. Grob, K.; J. High Resol. Chromatogr. 1983, 6, 178.

24. Olesik, S. V.; Pekay, L. A.; Chromatographia 1990, 29, 69.
25. Gere, D. R.; Board, R.; McManigill, D.; Anal. Chem. 1982, 54, 736.

26. Vindevogel, J.; Schuddinck, G.; Dewaele, C.; Verzele, M.; J. High Resol. Chromatogr. 1988, 11, 317.

27. Henry, C.; Anal. Chem. 1997, 69, 561A.

28. Peaden, P. A.; Lee, M. L.; J. Liq. Chromatogr. Relat. Technol. 1982, 5, 179.

29. Sjoberg, P. J. R.; Markides, K. E.; J. Chromatogr., A 1999, 855, 317.

30. Erickson, B.; Anal. Chem. 1997, 69, 683A.

31. Smith, R. D.; Udseth, H. R.; Anal. Chem. 1987, 59, 13.

32. Chapman, J. R.; Rapid Commun. Mass Spectrom. 1988, 2, 6.

33. Berry, A. J.; Games, D. E.; Mylchreest, I. C.; Perkins, J. R.; Pleasance, S.; Biomed. Environ. Mass Spectrom. 1988, 15, 105.

34. Chester, T. L.; Pinkston, J. D.; Raynie, D. E.; Anal Chem. 1998, 70, 301R.

35. Pinkston, J. D.; Bowling, D. J.; Anal. Chem. 1993, 65, 3534.

36. Pinkston, J. D.; Hentschel, R. T.; J. High Resol. Chromatogr. 1993, 16, 269

37. Berry, A. J.; Games, D. E.; Mylchreest, J. R.; Pleasance, S.; J. High Resol. Chromatogr. 1988, 11, 61 .

38. Mertens, M. A. A.; Janssen, H-G. M.; Cramers, C. A.; Genuit, W. J. L; Velzen, G. J.; Dirkzwager, H.; Binsbergen, H.; J. High Resol. Chromatogr. 1996, 19,17

39. Fuchslueger, U.; Socher, G.; Grether, H-J.; Grasserbauer, M.; Anal. Chem. 1999, 71, 2324.

40. Tuomola, M.; J. Chromatogr., B: Biomed. Sci. Appl. 1998, 719, 25.

41. Carrot, M. J.; Jones, D. C.; Davidson, G.; Analyst 1998, 123, 1827.

42. Tyrefors, L. N.; Moulder, R. X.; Markides, K. E.; Anal. Chem. 1993, 65, 2835.

43. Sadoun, F.; Virelizier, H.; Arpino, P. J.; J. Chromatogr., A 1993, 647, 351.

44. Harris, C. M.; Anal. Chem. 2002, 74, 87A.

45. Bargmann, N.; Tambute, A.; Caude, M.; Analusis 1992, 20, 189.

46. Bargmannleyder, N.; Sella, C.; Bauer, D.; Tambute, A.; Caude, M.; Anal. Chem. 1995, 67, 952.

47. Chester, T. L.; Pinkston, J. D.; Anal. Chem. 2000, 72, 129R.

48. Lanças, F. M. Em Dekker Encyclopedia of Chromatography; Cases, J., ed.; Marcel Dekker Inc.: USA, 2000.

49. Tavares, M. C. H.; Vilegas, J. H. Y.; Lanças, F. M.; Phytochem. Anal. 2000, 11,1 . 